\title{
Ring Resonator for Detection of Melting Brine under Shallow Subsurface of Mars
}

\author{
George E. Ponchak \\ NASA Glenn Research Center \\ 21000 Brookpark Rd., MS 77/1 \\ Cleveland, OH 44135 \\ 216-433-3504 \\ george.ponchak@grc.nasa.gov
}

\author{
Jennifer L. Jordan \\ NASA Glenn Research Center \\ 21000 Brookpark Rd., MS 77/1 \\ Cleveland, OH 44135 \\ 216-433-5661 \\ jennifer.l.jordan@nasa.gov
}

\author{
Maximilian C. Scardelletti \\ NASA Glenn Research Center \\ 21000 Brookpark Rd., MS 77/1 \\ Cleveland, OH 44135 \\ 216-433-9704 \\ maximilian.c.scardelletti@nasa.gov
}

\begin{abstract}
Laboratory experimental evidence using Raman spectroscopy has shown that liquid brine may form below the shallow subsurface of Mars. A simpler experimental method to verify the presence of liquid brine or liquid water below Mars surface is needed. In this paper, a ring resonator is used to detect the phase change from frozen water to liquid water below a sandy soil that simulates the Mars surface. Experimental data shows that the ring resonator can detect the melting of thin layers of frozen brine or water up to $15 \mathrm{~mm}$ below the surface.
\end{abstract}

\section{TABLE OF Contents}

1. INTRODUCTION. 1

2. RING RESONATOR DESIGN ................................2

3. DATA ANALYSIS....................................................... 4

4. Control TeStS............................................................4

5. MELTING BURIED ICE SAMPLE .............................. 7

6. MELTING FROZEN BRINE SAMPLE.......................8

7. SATURATED SAND DRYING ......................................99

8. SENSOR IMPLEMENTATION....................................10

9. CONCLUSIONS ..........................................................10

ACKNOWLEDGEMENTS.......................................10

REFERENCES ..................................................................10

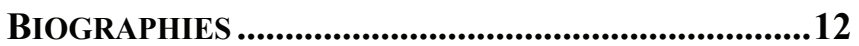

\section{INTRODUCTION}

The Phoenix Mars Scout mission discovered perchlorate salts, $\mathrm{Mg}\left(\mathrm{ClO}_{4}\right)_{2}$ and $\mathrm{Ca}\left(\mathrm{ClO}_{4}\right)_{2}$, in the Martian soil [1]. Perchlorate salts are hygroscopic, absorbing water present in the soil or atmosphere through deliquescence. Thermal and Electrical Conductivity Probe (TECP) data of the Martian soil during the Phoenix mission showed an increase in the real part of permittivity every Martian night, and it was hypothesized that this is due to absorption of water from the atmosphere by the soil or salts in the soil [2]. It was hypothesized that the thermodynamics of freeze-thaw cycles causes the formation of brine pockets in saline soils such as that of the Phoenix landing site [3], [4]. Further analysis of the TECP data showed an increase in permittivity during the day when water absorbed at night melts [5]. The increase in permittivity is small and indicates one or two monolayers of water. Furthermore, the data shows that the water cycle is due to $\mathrm{NaClO}_{4}$ or $\mathrm{MgCl}_{2}$, not $\mathrm{Mg}\left(\mathrm{ClO}_{4}\right)_{2}$ [5]. Phase diagrams of various salts show that $\mathrm{Mg}\left(\mathrm{ClO}_{4}\right)_{2}$ has the lowest eutectic temperature, but other salts may exist in the liquid state at temperatures that exist on Mars [6]. Raman spectroscopy conducted in a chamber that simulates the Mars environment demonstrated that liquid brine can form in the Mars shallow subsurface if salts are deposited on frozen water [7]. If proven to be correct, liquid saline-water could occur almost anywhere that ground ice is present near the surface of Mars [7]. The white material in the photo in Figure 1 is hypothesized to be frozen brine in the shallow subsurface of Mars. Because of the importance of discovering liquid water on Mars to further the search for life and possible long term manned missions to Mars, even if the liquid is brine, a low cost method of detecting it and confirming the Raman spectroscopy results is required.

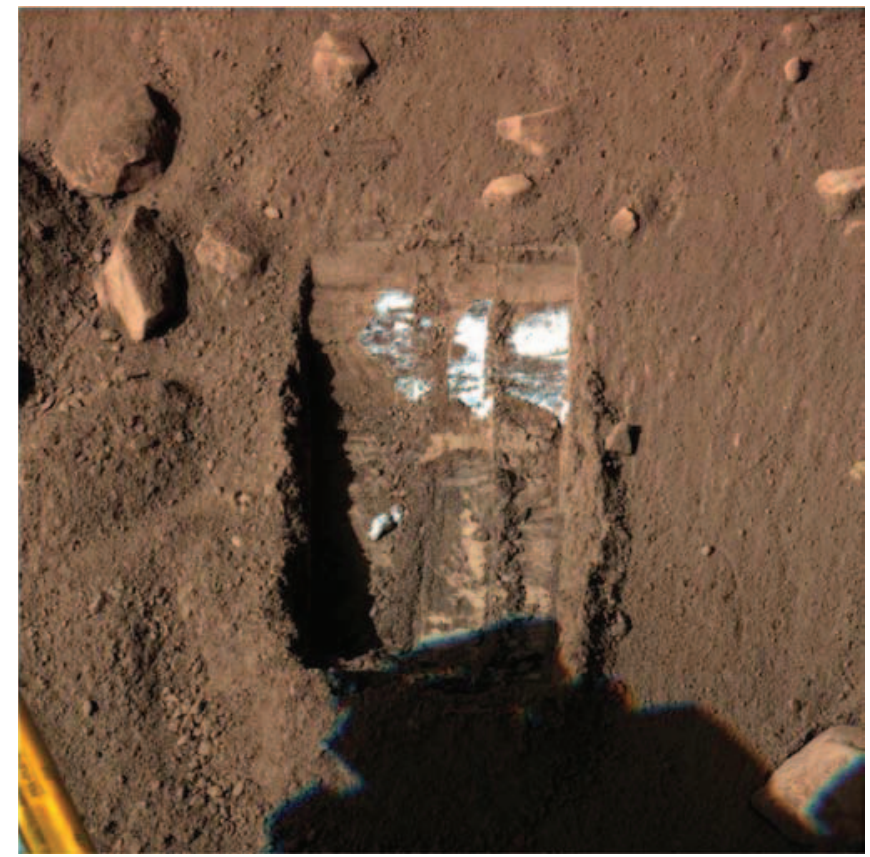

Figure 1: Photo from Mars Phoenix Lander of possible frozen brine in the shallow subsurface.

The real part of the relative permittivity $\left(\varepsilon_{\mathrm{r}}{ }^{\prime}-j \varepsilon_{\mathrm{r}}{ }^{\prime \prime}\right)$ of Martian soil was measured by the Phoenix Lander using the capacitance between two needles of a probe and a $6.25 \mathrm{MHz}$ signal to be between 2.5 and 2.8 , with an uncertainty due to inconsistent probe contact with the soil [2]. Measurements of different soil types on Earth show that the permittivity of dry soil is not very dependent on the type of soil. Hallikainen et al. showed that at $1.4 \mathrm{GHz}$, five dry soil types ranging from sandy loam to silty clay have a dielectric constant of $2.5-j 0$ [8]. 
Topp et al. measured mineral soil materials that replicate sandy loam through clay and reported real relative permittivities between 2.59 and 3.03 [9]. Vall-llossera et al. report a relative permittivity for dry sand of $2.45-j 0.019$ and a relative permittivity for dry clay of $3.54-j 0.55$ [10]. Mironov measured the permittivity at $1.4 \mathrm{GHz}$ of dry soils of approximately 2.5 [11], and the relative permittivity of dry sand was measured to be $2.5-j 0.06$ at $1 \mathrm{GHz}$ [12]. Thus, the permittivity of soils on Earth and Mars are similar and sand or sandy loam may be used to simulate Mars soil.

The permittivity of water has been well studied and various models have been proposed to fit the permittivity as a function of temperature and frequency. However, below $3 \mathrm{GHz}, \varepsilon_{\mathrm{r}}{ }^{\prime}$ is nearly constant and equal to the static value $[13,14,15]$ of 87.9 at $0{ }^{\circ} \mathrm{C}$ [14]. Measurements show that the real part of the static permittivity decreases with temperature at the rate of approximately $0.4 * \mathrm{~T}$ [14]. The imaginary part of the permittivity increases with frequency to approximately $10 \mathrm{GHz}$, after which it decreases with frequency [14]. Also, $\varepsilon_{\mathrm{r}}$ " decreases with increasing temperature below $10 \mathrm{GHz}[14$, $15]$.

The measured permittivity of sea water, which is a form of brine, has been studied for remote sensing [16, 17, 18, 19]. The permittivity is dependent on frequency, temperature, and salinity, but an in-depth experimental determination of the multi-variable permittivity is not available. However, below $3 \mathrm{GHz}$, which is the frequency of interest for this sensor, $\varepsilon_{\mathrm{r}}$, decreases as temperature increases from 0 to $40{ }^{\circ} \mathrm{C}[16,17$, 18]. Furthermore, $\varepsilon_{\mathrm{r}}{ }^{\prime}$ decreases as salinity increases [16, 17, 18]. The imaginary part of permittivity increases as temperature increases $[16,18]$ over the range of 0 to $40{ }^{\circ} \mathrm{C}$, but below $0^{\circ} \mathrm{C}, \varepsilon_{\mathrm{r}}{ }^{\prime}$ ' increases as temperature decreases [19]. At $0{ }^{\circ} \mathrm{C}$ and $3 \mathrm{GHz}, \varepsilon_{\mathrm{r}} \approx 71-j 39$ for sea water and $72-j 40$ for a $\mathrm{NaCl}$ solution of the same salinity [18].

Ice has a nearly constant real relative permittivity of approximately 3.15 above $100 \mathrm{kHz}$, and it does not vary by more than 0.1 over a temperature range from -80 to $0{ }^{\circ} \mathrm{C}[15$, 20]. However, the imaginary part of the permittivity increases by more than a factor of ten as the temperature increases over the $80{ }^{\circ} \mathrm{C}$ temperature range and the frequency range of $800 \mathrm{MHz}$ to $3 \mathrm{GHz}[20]$. At $0{ }^{\circ} \mathrm{C}$, the relative permittivity o f ice is approximately $3.15-j 0.0015$ [20]. Measurements of Beaufort Sea ice with salinity of $5 \%$ and over a temperature range of -4 to $-12{ }^{\circ} \mathrm{C}$ and frequency range of $1-5 \mathrm{GHz}$ indicate a permittivity of approximately $3.6-j 0.2$, with the real part increasing slightly with salinity [21].

Thus, water and brine have a similar real part of permittivity that is at least an order of magnitude greater than ice or the surrounding soil, which have approximately the same permittivity. Moreover, the imaginary part of permittivity of water is greater than dry soil or ice by approximately four orders of magnitude in the microwave frequency range. Thus, microwave measurement techniques should be able to detect the melting of ice and measure the moisture content of soil.
Time delay measurements of either the reflection coefficient [22] or transmission coefficient [23] have been demonstrated with the ability to determine the depth of variations in the soil type. The resonant frequency and quality factor of a coaxial resonator with a slot in the outer conductor [24] or a monopole resonator [25]; the reflection coefficient of a flared, open circuit coaxial transmission line [26], wire probes extended from the center and outer conductors of a coaxial transmission line [27], and a dielectric waveguide flared radiator [28]; and a two wire capacitive probe [29] have been demonstrated to measure soil moisture content. However, each of these probes requires the probe to be inserted into the soil, which cannot have rocks or be frozen if the sensor is not to be damaged.

Microstrip resonators with a defected ground plane [30, 31], microstrip open circuit stubs [32], microstrip transmission lines coupled to complementary split-ring resonators in the ground plane [33], and microstrip ring resonators [34, 35] have also been proposed to measure the moisture content of soils due to the change in permittivity as a function of moisture content. The microstrip resonators are either placed on top of the soil or buried in the soil and couple to the soil through the defected ground planes or through interaction of the electromagnetic fields of the microstrip lines. In these previous demonstrations, the soil is uniformly moist, and thus the resonant frequency of the resonator varies due to the bulk permittivity of the soil. Also, because the bulk permittivity is being measured, no characteristics of the soil as a function of depth were measured. However, because the liquid brine or water on Mars will exist in thin layers below the shallow subsurface, measuring the bulk permittivity of the soil is not what is required.

In this paper, a ring resonator is used to characterize a thin layer of moist soil below the dry surface. The results from control experiments using water and brine simulant are presented to demonstrate the usefulness of the ring resonator for this application. Then, the characteristics of the resonator for detecting the melting of a thin layer of ice below the soil are presented. Finally, the characteristics of a saturated sandy soil that dries in the sun are presented.

\section{Ring RESONATOR DESIGN}

The ring resonator design is similar to that described in [34] and is shown in Figure 2. The substrate is Rogers TMM 3, which has a relative permittivity of 3.27 and a thickness of $3.15 \mathrm{~mm}$. TMM substrate is chosen because it has a low thermal coefficient of permittivity $\left(+37 \mathrm{ppm} /{ }^{\circ} \mathrm{C}\right)$ [36], it can easily be machined, and it has low outgassing [37]. The microstrip ring resonator has an outer diameter of $64.7 \mathrm{~mm}$ and a microstrip width of $3.7 \mathrm{~mm}$. The ring resonator will have transmission maximums or resonances at frequencies when the circumference of the ring is a multiple of the guided wavelength ( $\lambda_{g}=n \pi d$, where $\lambda_{g}$ is the guided wavelength, $d$ is the diameter and $n=1,2,3 \ldots$ ), assuming that the coupling reactances are negligible. When the ring is placed on a material, the guided wavelength is changed and the resonant frequency changes. The microstrip ring resonator is capacitively coupled to coaxial cables by symmetrically 
placing two coax launchers on the ground plane with the outer conductor of the coax launcher soldered to the ground plane and the center pin of the coax launcher extended partially through the substrate and directly under the middle of the microstrip line. The amount of capacitive coupling is controlled by the distance between the center pin and the microstrip line. In the ring resonator used here, a $2.65 \mathrm{~mm}$ deep hole is drilled in the $3.15 \mathrm{~mm}$ thick substrate and the center pin is $2.65 \mathrm{~mm}$ long, resulting in a coupling gap of $0.5 \mathrm{~mm}$. This arrangement has the advantage that the coupling capacitance is not dependent on the material placed over the substrate, and thus, it is ideally suited for soil moisture measurements. If the coupling capacitance were dependent on the surrounding material, the resonant frequencies would not be only dependent on the guided wavelength of the microstrip line.

Experimentally, it was observed that the decrease in the quality factor, Q, of the resonator when it is placed directly on wet soil samples decreased the sensitivity of the measurements. Therefore, a $0.76 \mathrm{~mm}$ thick TMM 10i, relative permittivity equal to 9.8 , superstrate was used to isolate the resonator from soil with high moisture content. TMM 10i is chosen because its thermal coefficient of permittivity is $-43 \mathrm{ppm} /{ }^{\circ} \mathrm{C}$ [36], which is approximately opposite to that of the substrate and should minimize the temperature dependence of the resonant frequency. The higher permittivity of the superstrate increases the power of the electromagnetic fields in the superstrate and the soil and increases the sensitivity of the resonator. This was verified with Sonnet High Frequency Electromagnetic Software simulations performed of the microstrip line with $0.76 \mathrm{~mm}$ thick superstrates of different permittivities as a function of the depth of a buried $2 \mathrm{~mm}$ thick, $\varepsilon_{\mathrm{r}}=72$ lossless water layer in dry sand.

The ring resonator can be used to measure the fundamental and all higher harmonic frequencies, but the data presented here is limited to the first three resonances because wet sand attenuates the higher frequency resonances too much for data analysis. A photograph the typical test setup is shown in Figure 3, where the sample is positioned on a scale to measure the weight of the sample so as to monitor any evaporation and to determine the moisture content. A thermocouple is buried below the sample and the temperature is recorded throughout the test. A typical resonator transmission characteristic is shown in Figure 4.

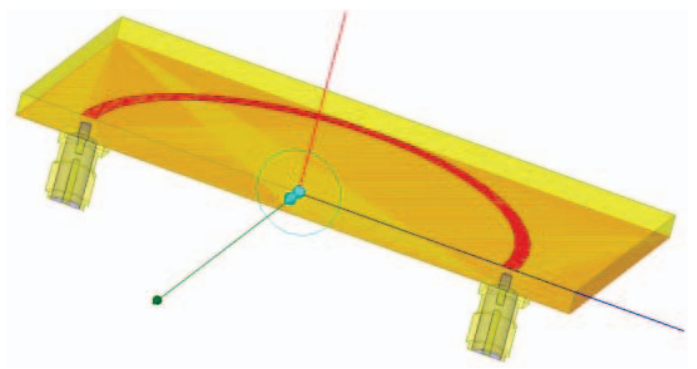

(a)

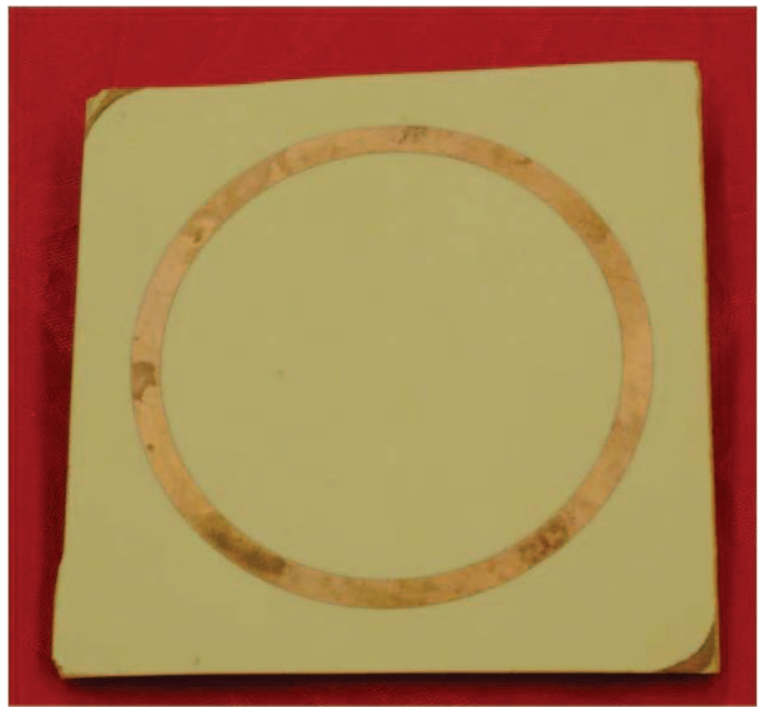

(b)

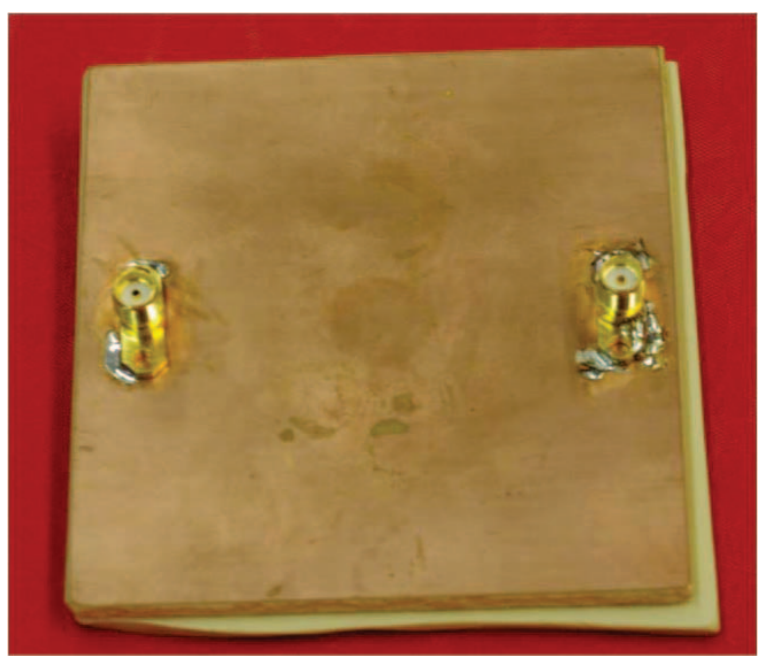

(c)

Figure 2: (a) Computer modeling cross-section of the ring resonator. The superstrate is not shown for clarity. (b) Photograph of ring resonator without the superstrate. (c) Photograph of the back side of the ring resonator with coax launcher.

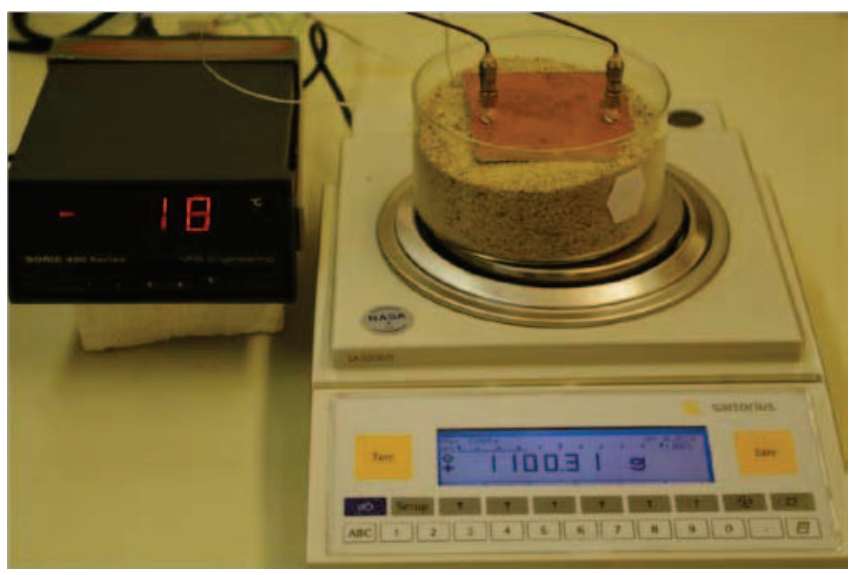

Figure 3: Photograph of test setup. 


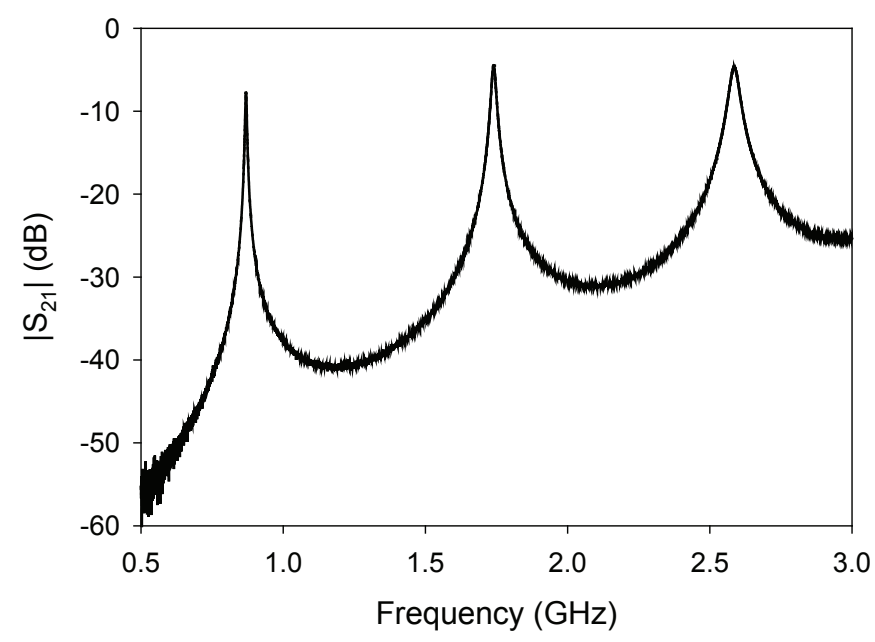

Figure 4: Typical transmission characteristics of a resonator with no Material Under Test (MUT) or air as the MUT.

\section{Data Analysis}

The resonator characteristics are measured on an Agilent PNA with a semi-rigid coaxial cable between the PNA and the coaxial connectors on the resonator. For all tests, the PNA is in the step mode and the number of points is set to a minimum of 3,000 data points per $\mathrm{GHz}$ of bandwidth. Prior to measurements, a Short-Open-Load-Through (SOLT) calibration is performed.

For data analysis, a search routine is used first to find the frequencies of the first three resonances, determined by the frequency of the maximum $\left|S_{21}\right|$. Then, a four parameter Lorentzian distribution is fit to a frequency range around the resonant frequency of either $4 \%$ or Full Width at Half Maximum (FWHM), whichever is greater.

$$
\left|S_{21}\right|=y_{0}+a \frac{1}{1+\frac{\left(f-f_{n}\right)^{2}}{b^{2}}}
$$

$f$ is the frequency, $f_{n}$ is the resonant frequency, $b$ is one half FWHM, and $\left|\mathrm{S}_{21}\right|_{\max }=y_{0}+a$. From the fit parameters, the resonant frequency and $Q_{n}\left(Q_{n}=f_{n} / 2 b\right)$ of the resonance is determined.

Before each measurement, the resonator is suspended above the sample at a sufficient height that the sample does not interact with the resonator, and the unloaded characteristics of the resonator are measured. Then, based on the measurement of the loaded and unloaded resonator characteristics, the procedure developed in [34] may be used to determine:

and:

$$
Q_{d, n}=\frac{Q_{n} Q_{n, a i r}}{Q_{n, a i r}-Q_{n}}
$$

$$
\frac{f_{n}}{f_{n, \text { air }}}=\frac{\sqrt{\varepsilon_{e f f, a i r}^{\prime}}}{\operatorname{Re} \sqrt{\varepsilon_{\text {eff }}^{\prime}}}
$$

where $Q_{n}$ is the quality factor of the nth harmonic of the loaded resonator and $Q_{n \text {,air }}$ is the quality factor of the nth harmonic of the unloaded resonator. $Q_{n \text {,air }}$ accounts for the conductor losses in the microstrip line, the dielectric losses in the substrate and superstrate, and radiation losses. When the resonator is placed over the sample, it is assumed that these losses do not change. Thus, $Q_{d, n}$ is the quality factor of the soil sample and accounts for the dielectric losses of the sand and water or brine in the sand. $f_{n \text {,air }}$ is the nth harmonic frequency of the unloaded resonator, $f_{n}$ is the nth harmonic frequency of the loaded resonator, $\varepsilon_{\text {eff,air }}$ is the effective permittivity of the unloaded microstrip, and $\varepsilon^{\prime}$ eff is the effective permittivity of the microstrip line when placed over the sample. Because we are interested in detecting the presence of thin layers of subsurface brine, the soil will not be homogeneous and the bulk effective permittivity of sample is not of interest. However, measuring a change in the resonant frequency, $f_{n}$, and $Q_{d}$ is of interest because this will indicate a melting of the frozen brine.

For the resonator suspended in air with a typical response shown in Figure 4, the first three resonant frequencies are $f_{n \text {,air }}$ equal to $0.864,1.734$, and $2.577 \mathrm{GHz}$ with corresponding unloaded quality factors, $Q_{n, \text { air }}$, of $97.4,70.2$, and 48.9, respectively.

The data reported in this paper is based on a frequency increment of approximately $275 \mathrm{kHz}$. However, through experimentation with the frequency increment in the data set, a frequency increment of $4.375 \mathrm{MHz}$ yielded results that would have allowed the conclusions of this paper to be made if the resonances are well behaved. As will be discussed below, split resonances were measured in some cases and the 4.375 MHz increment would not have yielded good results in those cases. Thus, the smaller frequency increment enables a better determination of $f_{n}$ and $Q_{d}$.

\section{Control Tests}

Because thin layers of melting brine under the soil subsurface will not change the permittivity of the bulk soil significantly, the sensitivity of the resonator characteristics to variations in temperature are first measured. The minimum recorded surface temperature on Mars is $-140{ }^{\circ} \mathrm{C}$, the mean surface temperature is $-63{ }^{\circ} \mathrm{C}$, and the maximum recorded temperature is $20{ }^{\circ} \mathrm{C}$ [38]. The resonator with and without the superstrate were measured in a chamber from $-75^{\circ} \mathrm{C}$ to $+40{ }^{\circ} \mathrm{C}$. The variation in the resonant frequency $\left(\left(f_{n}\left(-75^{\circ} \mathrm{C}\right)-\mathrm{f}_{\mathrm{n}}(\mathrm{T})\right) / \mathrm{f}_{\mathrm{n}}\left(-75^{\circ} \mathrm{C}\right)\right)$ for the first three resonances is shown in Figure 5. It is observed that with the superstrate the resonant frequency increases with temperature more than is predicted by the datasheet thermal coefficient of permittivity, but the percent change is small. Furthermore, because the 
resonant frequency of the unloaded resonator with the superstrate increases with temperature and the resonant frequency of the resonator loaded by the soil should decrease with melting ice or brine, there should not be false indications of melting brine due to thermal variations. Optimum material choices for the substrate and superstrate would result in no variation in the resonant frequency with temperature, which would increase the sensitivity of the sensor. As expected, the $Q_{d}$ decreases with increasing temperature due to increase in copper resistivity with temperature.

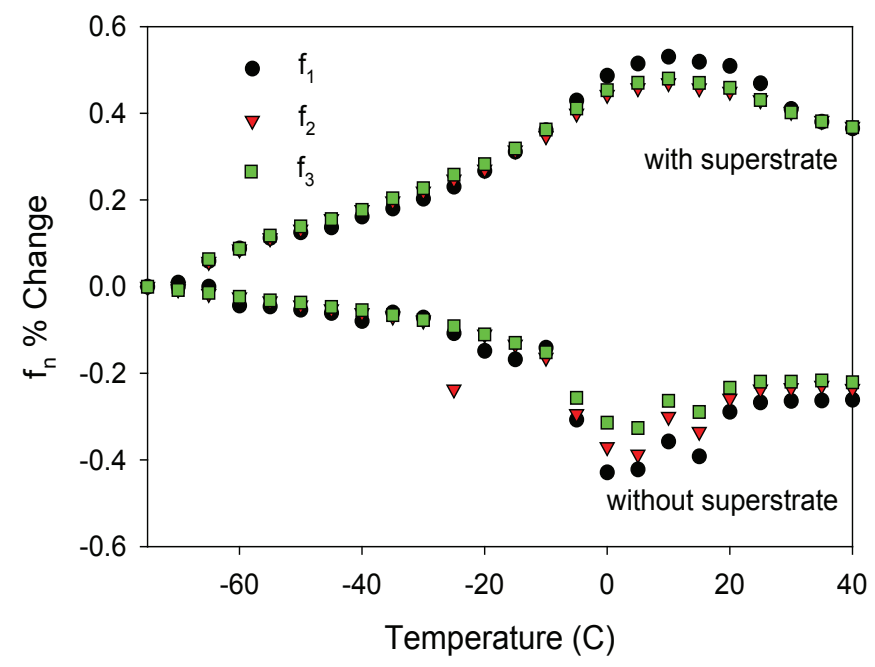

(a)

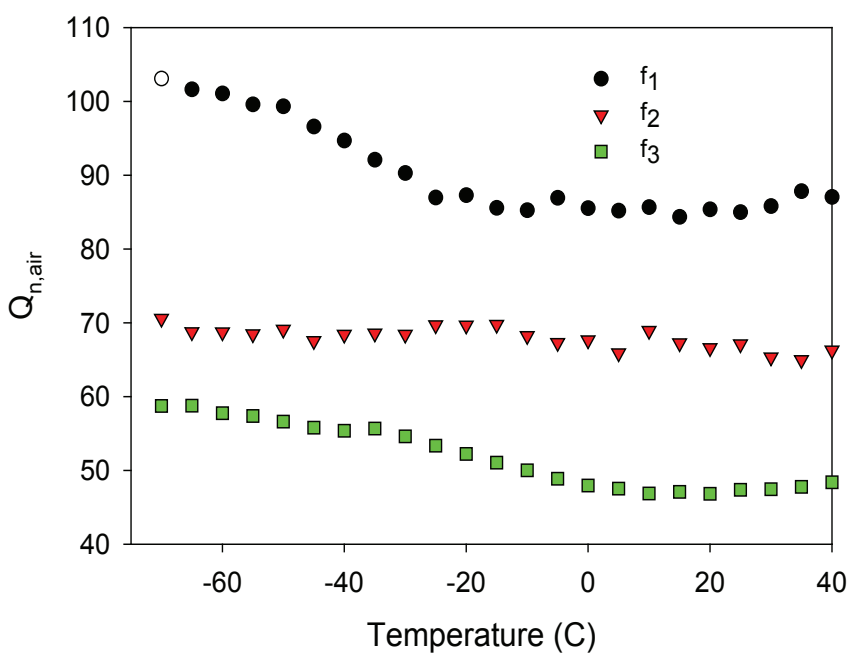

(b)

Figure 5: Measured variation in (a) resonant frequency as a function of temperature of unloaded resonator with and without the superstrate (b) $Q$ as a function of temperature of unloaded resonator with the superstrate.

If the ice melts in a very hard packed soil or if the soil below the ice is frozen so that the soil is impenetrable to water, the melted ice will form groundwater. Because this is not an easy circumstance to duplicate in the laboratory, four controlled experiments were established. Each uses layers of RT/Duroid
5880 , which has a relative permittivity of 2.2 and $\varepsilon_{\mathrm{r}}{ }^{\prime}=0.001$, to simulate dry sand, and the temperature of the experiment is $23{ }^{\circ} \mathrm{C}$. The first experiment uses a $1.4 \mathrm{~mm}$ thick layer of TMM $10 \mathrm{i}, \varepsilon_{\mathrm{r}}{ }^{\prime}=9.8$ and $\varepsilon_{\mathrm{r}}{ }^{\prime}=0.02$, to simulate a layer of moist sand. The second experiment uses a $0.65 \mathrm{~mm}$ thick layer of ceramic that has a relative permittivity of 67.5 , which is close to the permittivity of water, but its imaginary permittivity is very low. In the third and fourth experiments, a cavity is machined in one layer of RF/Duroid that holds $2 \mathrm{~mm}$ by $40 \mathrm{~mm}$ by $40 \mathrm{~mm}$ of deionized water and brine solution $\left(50 \mathrm{~g}\right.$ DI $\mathrm{H}_{2} \mathrm{O}$ mixed with $5 \mathrm{~g}$ of Instant Ocean aquarium salt), respectively. The resonator is placed over a stack of RT/Duroid, and the depth of the MUT is varied within the RT/Duroid stack.

Figure 6 shows the change in $f_{n} / f_{n \text {,air }}$ for the test cases of lossless materials with permittivities of 9.8 and 67 . Note that the change is greater for the higher permittivity material, but the maximum depth that the material can be detected is $10 \mathrm{~mm}$ in each case. Also, there is not a significant difference in the change in resonant frequency for the first three resonances. The quality factor $Q_{d}$ is not shown because the materials have a small $\varepsilon_{\mathrm{r}}$ "', causing the measured $Q_{n}$ for the loaded and unloaded resonators to be almost equal and $Q_{d}$ to be mathematically indeterminate.

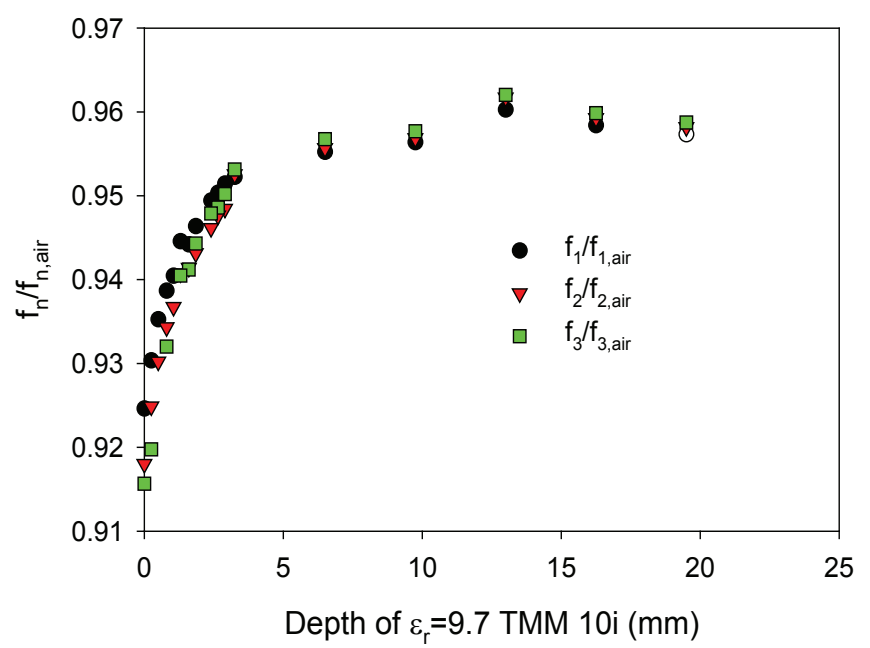

(a) 


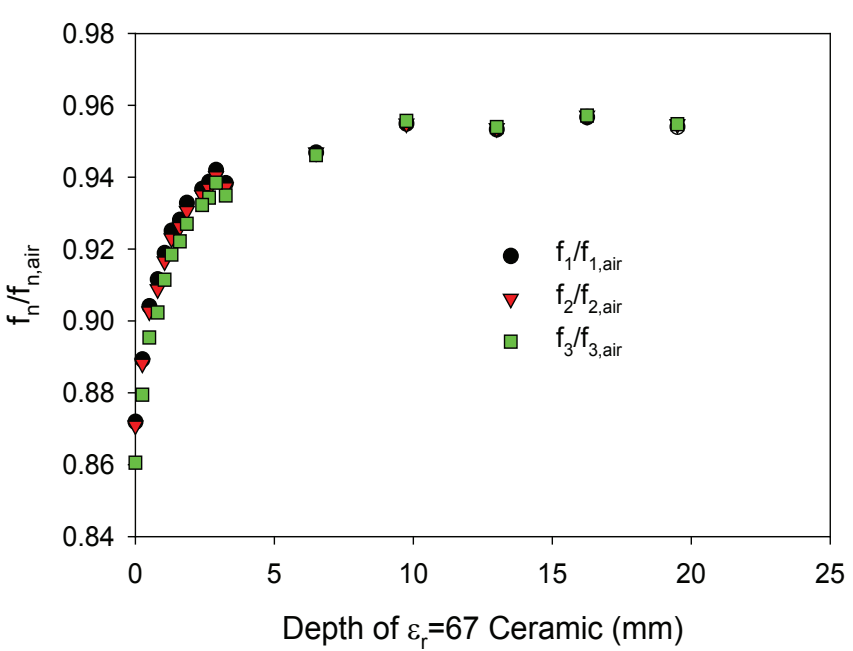

(b)

Figure 6: Measured variation in resonant frequency as a function of depth for (a) $1.4 \mathrm{~mm}$ thick $\varepsilon_{\mathrm{r}}=9.8$ TMM $10 \mathrm{i}$ board, (b) $0.65 \mathrm{~mm}$ thick $\varepsilon_{\mathrm{r}}=67$ ceramic boards buried in RT/Duroid 5880.

Figure 7 shows the measured variation in the resonant frequency and Figure 8 shows the measured $Q_{d}$ for the test cases with water and brine. Note that $Q_{d}$ is very small $(<10)$ for all resonances of a brine sample and for the higher harmonics for a water sample within a few millimeters below the surface, and this degrades the accuracy of the determination of the resonant frequency. Furthermore, although it is not shown, there is a splitting of the resonance, especially when the sample is within a few millimeters of the surface, for some of the measurements. In these cases, if one of the resonances has a peak in $\left|S_{21}\right|$ such that its FWHM is narrow enough not to include the second resonance, the Lorentzian fitting was done around that resonance. If the two resonant peaks have a similar magnitude, the Lorentzian equation is fit to a frequency range that spans both resonances. In these two cases, the Lorentzian distribution cannot accurately fit these data samples resulting in scatter in the data. The splitting of the mode is due to non-uniformities, such as air bubbles, in the sample under the resonator [39], and since the frozen brine will not be uniformly distributed or uniformly melt, this mode splitting will be observed in practice. Even with the mode splitting, Figure 7 shows that a significant change in the resonant frequency may be measured, slightly greater than the $\varepsilon_{\mathrm{r}}=67$ ceramic sample, but if only $\mathrm{f}_{\mathrm{n}}$ is observed, the sample may only be detected to within $10 \mathrm{~mm}$ of the surface. However, there is a significant variation in $Q_{d}$ for samples of water and brine in the subsurface, and by using the first three resonances, it should be possible to detect water or brine up to $20 \mathrm{~mm}$ below the surface. It may also be noted that resonance splitting may be used to indicate the size of the frozen brine; if there is no splitting, that is an indication that the brine layer is larger than the resonator, and if there is splitting, that is an indication that the area of the brine layer is less than the diameter of the resonator.

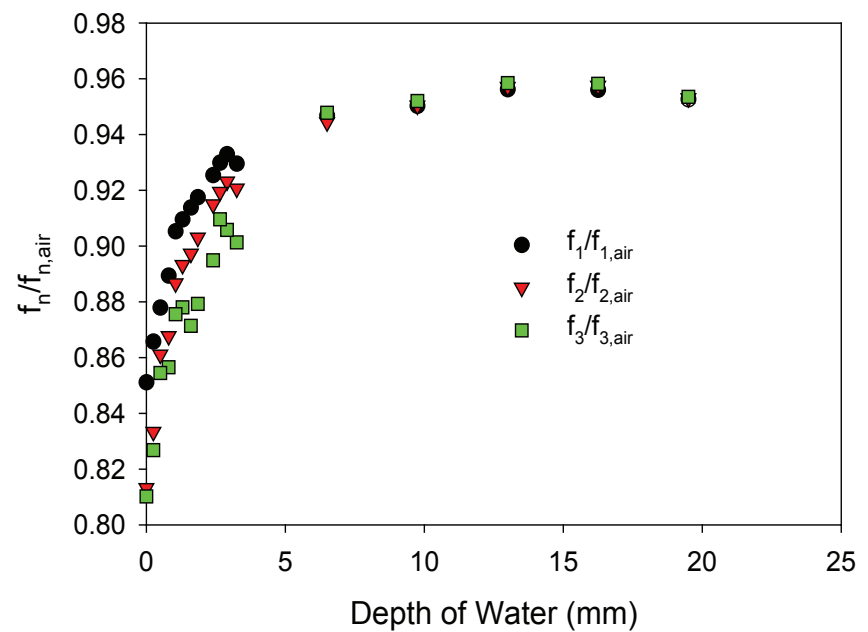

(a)

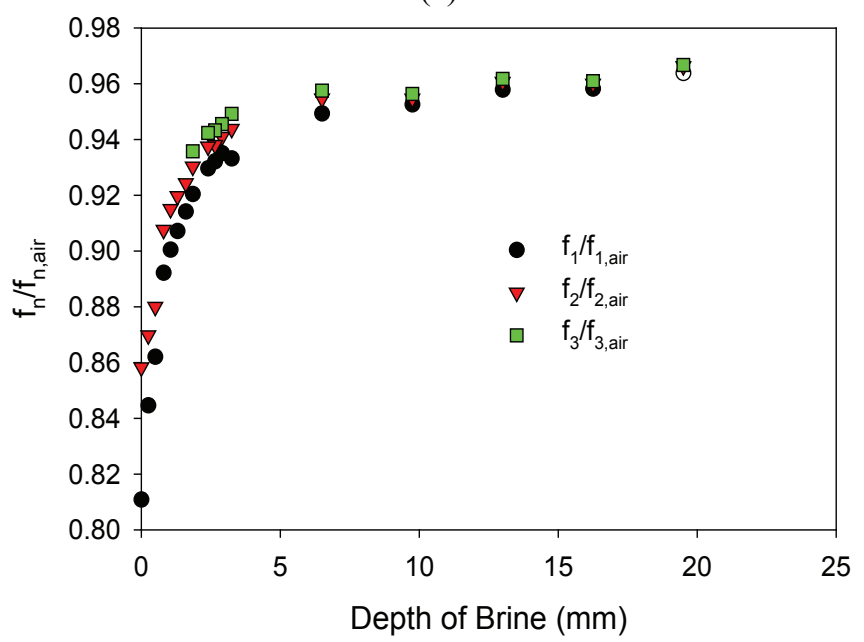

(b)

Figure 7: Measured variation in resonant frequency as a function of depth for (a) $\mathbf{2} \mathbf{~ m m}$ thick layer deionized water, (b) $2 \mathrm{~mm}$ thick layer brine buried in RT/Duroid 5880 .

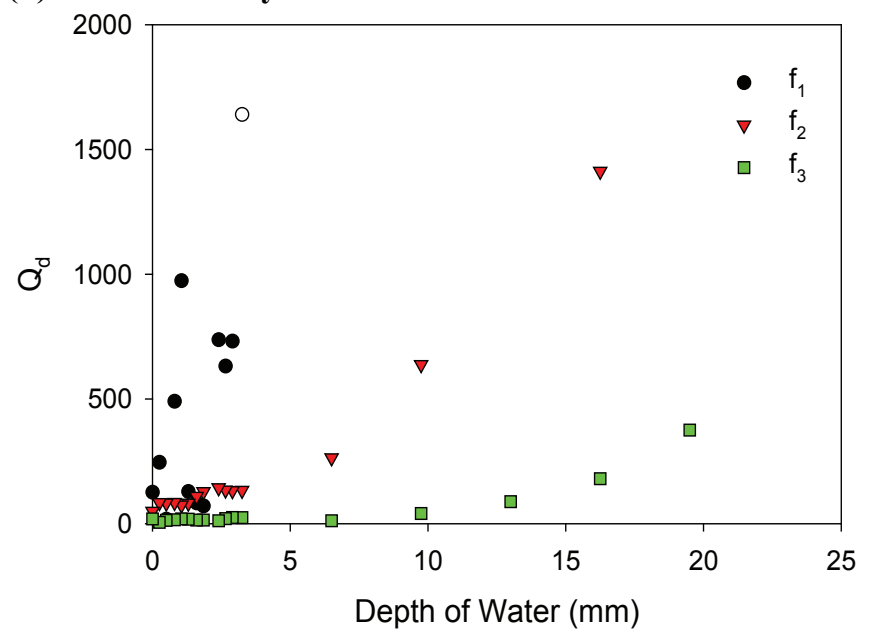

(a) 


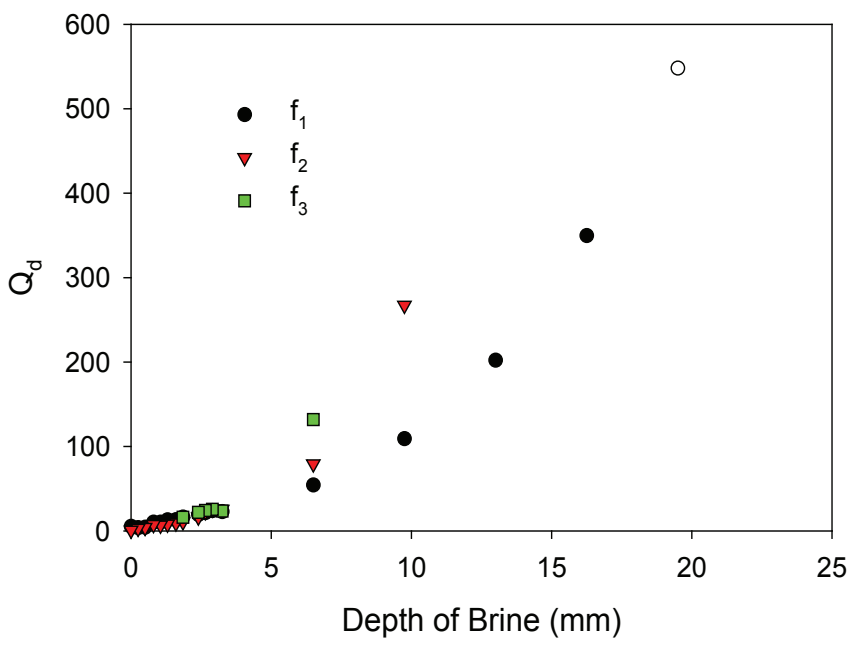

(b)

Figure 8: Measured $Q_{d}$ as a function of depth for a $2 \mathrm{~mm}$ thick layer (a) deionized water, (b) brine buried in RT/Duroid 5880.

\section{Melting Buried ICE SAMple}

To verify that the ring resonator can detect when thin layers of frozen water buried in cold sand changes from the solid to liquid state, frozen deionized water samples were prepared and buried under frozen, dry sand in a $125 \mathrm{~mm}$ deep quartz dish. The sand was approximately $50 \mathrm{~mm}$ thick and the ice samples were approximately $2.5 \mathrm{~mm}$ thick. Two experiments were conducted with the ice buried approximately $7.5 \mathrm{~mm}$ and $15 \mathrm{~mm} \pm 2 \mathrm{~mm}$ beneath the surface. The experiments were conducted in a laboratory at $25{ }^{\circ} \mathrm{C}$ and the samples were allowed to warm to room temperature during the tests. A thermocouple was buried in the sand below the ice layer and the results are plotted relative to that temperature. However, it must be noted that the volume of sand was small and the temperature of the sand was not uniform. By placing the thermocouple below the sand, it should have given a good indication of the sand in the region of the ice. Because the humidity of the laboratory was not controlled or near zero, condensation was observed on the quartz dish and the top of the sand during the test.

Because the volume of sand was large compared to the ice sample, when the ice melts, the moisture content of the sand was very non-uniform. The moisture content increased in the volume around the ice as the ice melts, and it decreased with time as the water disperses throughout the sand. It was observed that the sand below the resonator had a higher moisture content than the sand exposed to air due to evaporation. However, during the measurement, the weight of the sand/water sample was measured and no significant weight loss was detected, indicating that very little evaporation occurred.

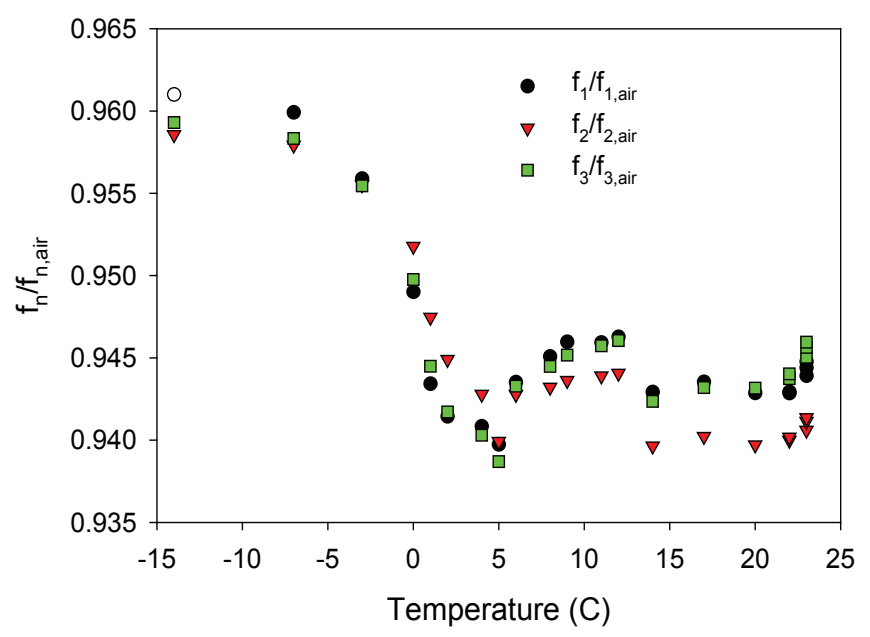

(a)

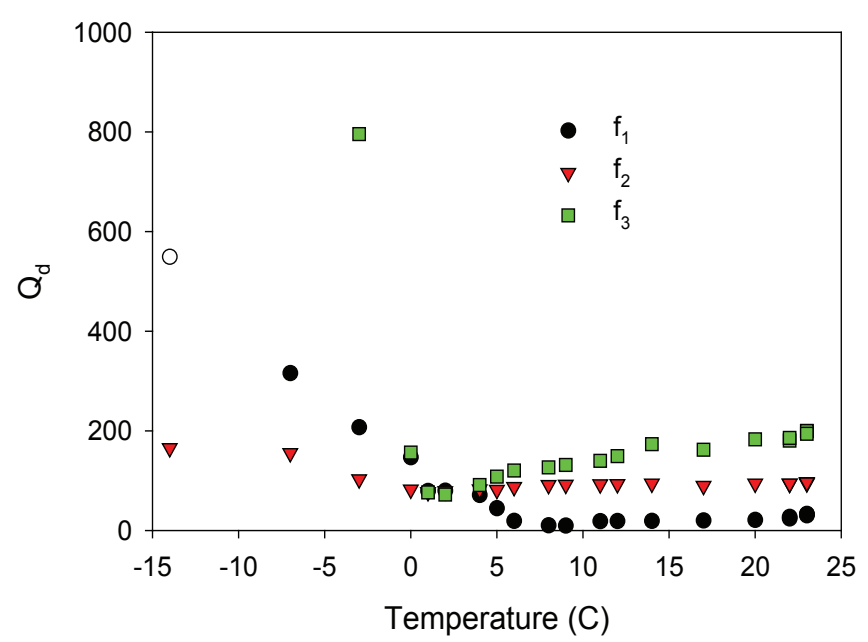

(b)

Figure 9: Measured variation in (a) resonant frequency and (b) $Q_{d}$ of a $2.5 \mathrm{~mm}$ thick water ice layer buried $7.5 \mathrm{~mm}$ below the surface of sand as a function of sand temperature.

Figures 9 and 10 show the measured $f_{n} / f_{n, \text { air }}$ and $Q_{d}$ for the ice buried $7.5 \mathrm{~mm}$ and $15 \mathrm{~mm}$, respectively, as a function of temperature. There is an immediate, measureable decrease in the resonant frequency as the ice melts and locally increases the moisture content of the sand, but the actual change in resonant frequency is small. The reduction in the quality factor is significantly larger and easier to measure and detect. As the water disperses throughout the sample, the resonant frequency and quality factor increases to that of the original dry sand. It is noted that the melting of a thin layer of ice buried $15 \mathrm{~mm}$ below the surface can be detected by the large change in quality factor. 


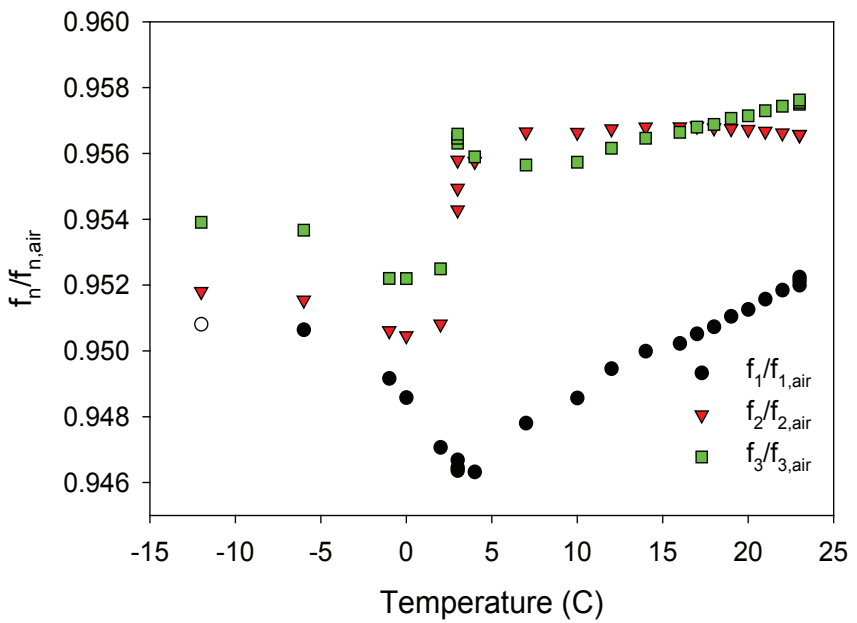

(a)

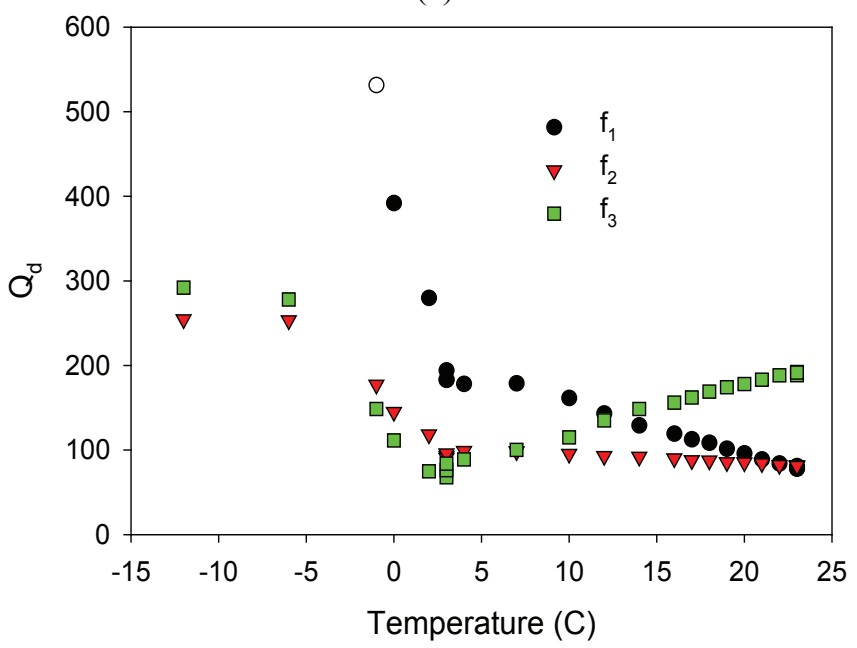

(b)

Figure 10: Measured variation in (a) resonant frequency and (b) $Q_{d}$ of a $2.5 \mathrm{~mm}$ thick water ice layer buried $15 \mathrm{~mm}$ below the surface of sand as a function of sand temperature.

\section{Melting Frozen Brine Sample}

$2.5 \mathrm{~mm}$ thick frozen brine samples were prepared in the same way as the frozen water samples of Section 5 and buried 7.5 and $15 \mathrm{~mm} \pm 2 \mathrm{~mm}$ below the surface of the sand. The experimental procedure is the same as in Section 5. The buried thermocouple for the $7.5 \mathrm{~mm}$ thick test was placed too close to the edge of the dish and warmed quicker than the sand around the ice, which affected the results in Figure 11. Figures 11 and 12 show the measured variation in resonant frequency and quality factor as a function of temperature for the frozen brine sample buried $7.5 \mathrm{~mm}$ and $15 \mathrm{~mm}$ below the surface, respectively. There is a measureable decrease in the resonant frequency from the start of the test until the ice has melted, after which the resonant frequency increases to a value that would be expected for sand with a specific moisture content. Note that there appears to be a minimum in the resonant frequency at the time that the ice melts. The quality factor data is not as easy to understand, and the measurement was repeated twice to verify the observations shown. For the
$7.5 \mathrm{~mm}$ depth ice brine, $Q_{d}$ decreases for the three resonant frequencies as the ice melts and stabilizes to a value expected for moist sand. For the $15 \mathrm{~mm}$ depth ice brine, $Q_{d}$ decreases as the ice melts, but the observations for the three resonant frequencies are not similar. Note that the same is true for the deionized water ice sample data shown in Figure $10 \mathrm{~b}$.

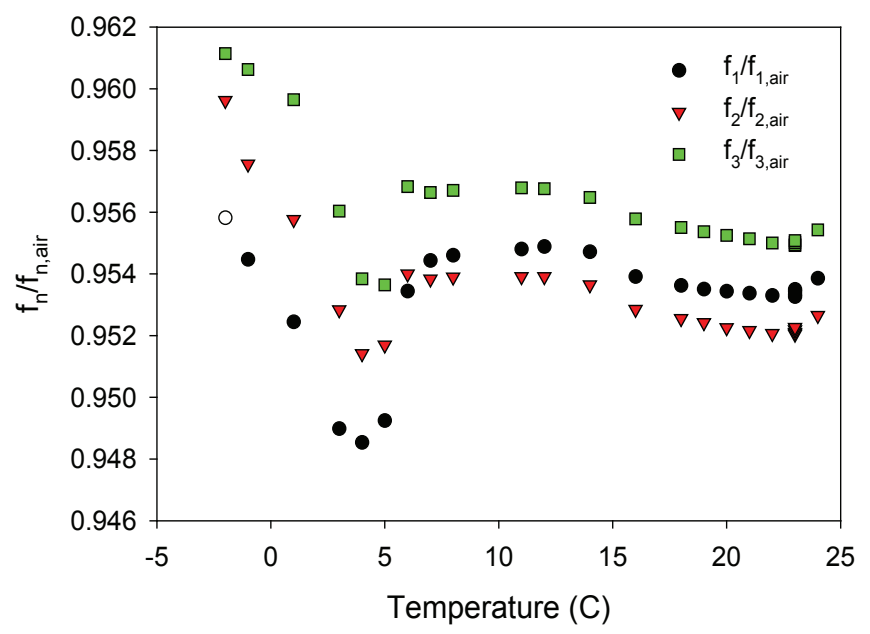

(a)

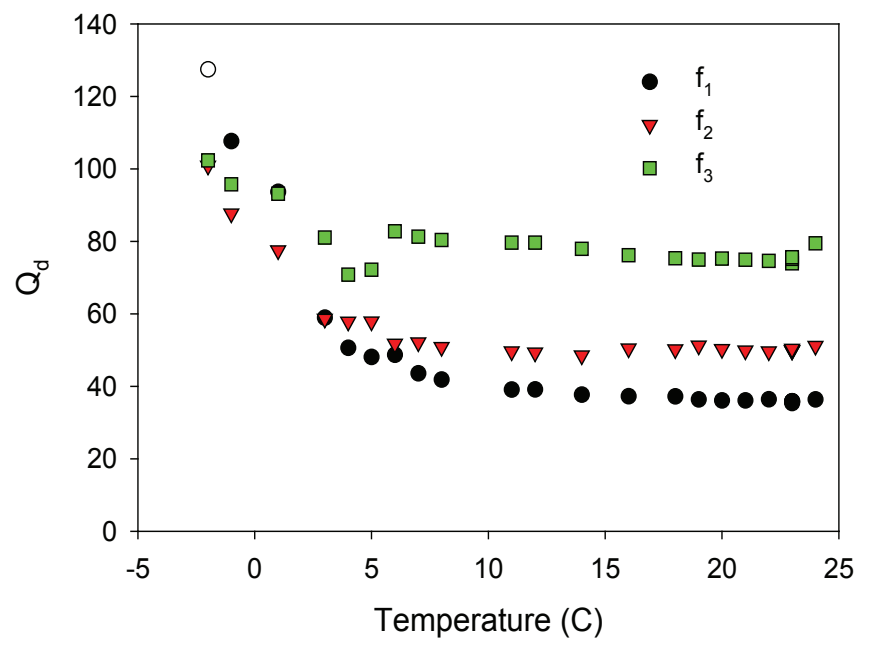

(b)

Figure 11: Measured variation in (a) resonant frequency and (b) $Q_{d}$ of a $2.5 \mathrm{~mm}$ thick frozen brine layer buried $7.5 \mathbf{m m}$ below the surface of sand as a function of sand temperature. 


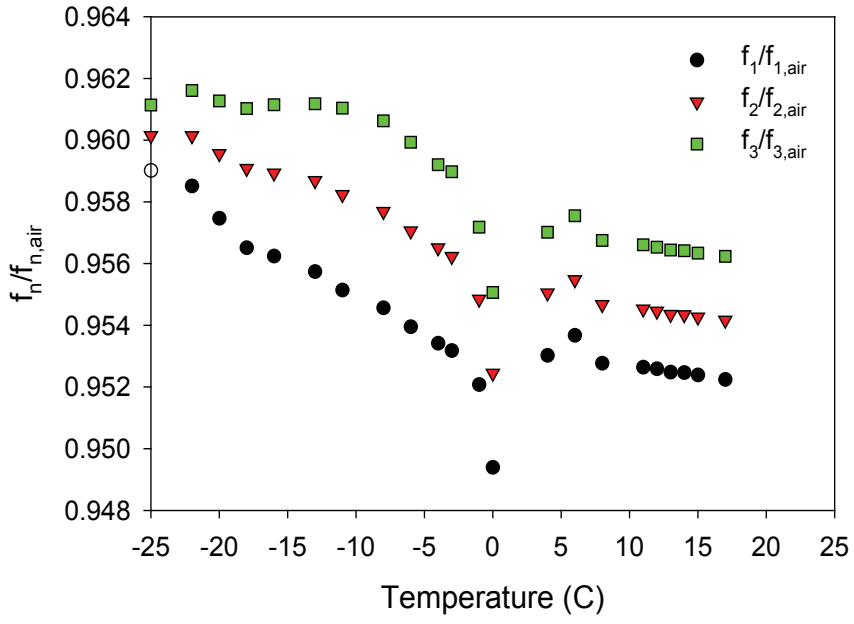

(a)

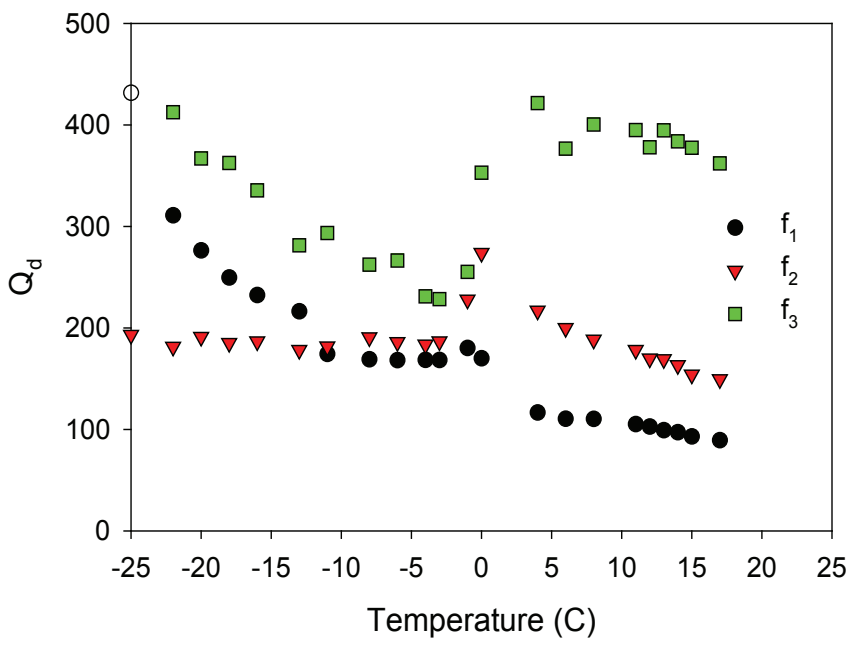

(b)

Figure 12: Measured variation in (a) resonant frequency and (b) $Q_{d}$ of a $2.5 \mathrm{~mm}$ thick frozen brine layer buried $15 \mathrm{~mm}$ below the surface of sand as a function of sand temperature.

\section{SATURATEd SAND DRYing}

Although not likely on Mars, if the ice layer is very large, it will saturate the sandy soil when it melts. To simulate the case of a sandy soil saturated with water and drying in the sun, a $150 \mathrm{~mm}$ diameter dish was filled with sand to a depth of $50 \mathrm{~mm}$ and deionized water was poured over the sand until just before the water "puddled" on the surface. To simulate the sun, two heat lamps were placed over the setup, which raised the temperature of the sand and resonator to $50{ }^{\circ} \mathrm{C}$. It is understood that Mars will not reach $50{ }^{\circ} \mathrm{C}$, but the high temperature was required to shorten the time of the test to two days. The sand/water mixture was placed on a scale and the mass of the mixture was weighed and the S-parameters were measured as a function of time. After the test was complete, the sand was dried in a $140{ }^{\circ} \mathrm{C}$ oven for $48 \mathrm{~h}$ and weighed to determine the dry sand mass. From the wet sand mass weighed during the test and the dry sand mass, the gravitational moisture content $\left(\mathrm{M}_{\mathrm{g}}=\mathrm{M}_{\mathrm{w}} /\left(\mathrm{M}_{\mathrm{w}}+\mathrm{M}_{\text {sand }}\right)\right)$, where $\mathrm{M}_{\mathrm{w}}$ is the mass of the water and $\mathrm{M}_{\text {sand }}$ is the mass of the dry sand) is determined. Initially, the saturated sand mixture has a homogeneous moisture content, but during the test, the top of the sand mixture dries due to the heat lamps and gravity forces the remaining water to the bottom similar to what would happen in nature. Since the resonator is only sensitive to changes in the sand/water permittivity to a depth of approximately $15 \mathrm{~mm}$ as evidenced by the prior results, the measured change in resonant frequency and $Q_{d}$ is nonlinear and saturates once the top $15 \mathrm{~mm}$ of sand dries.

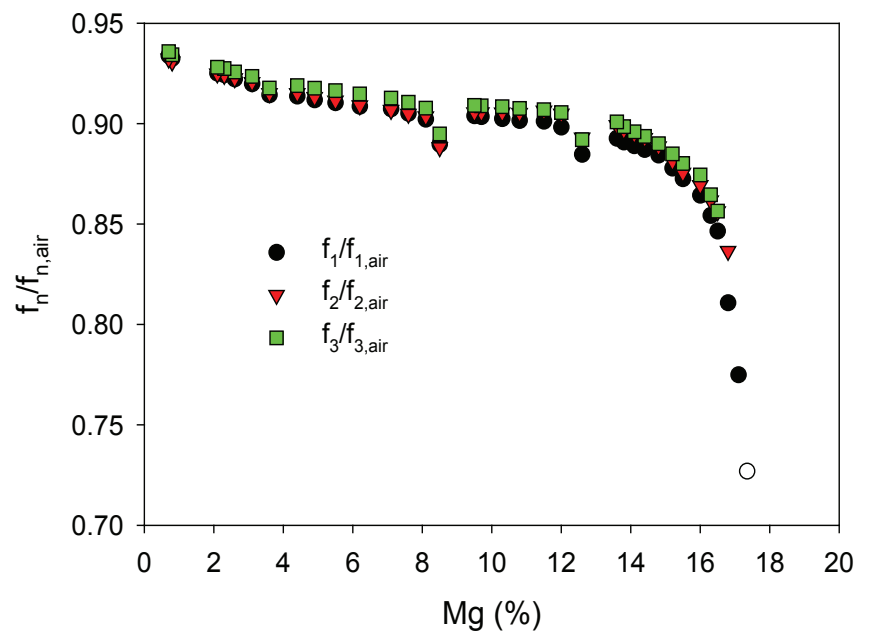

(a)

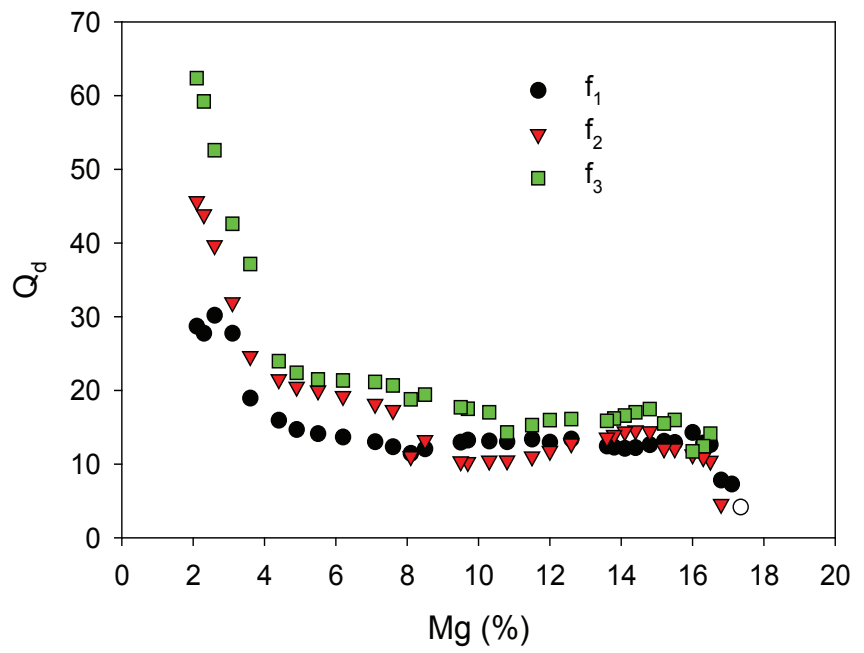

(b)

Figure 13: Measured variation in (a) resonant frequency and (b) $Q_{d}$ as a function of $M g$.

The quality factor of the resonator is too low for moisture contents greater than $16 \%$, especially for the second and third harmonic frequencies, to obtain the resonant frequency. Figure 13 shows the change in resonant frequency and $Q_{d}$ as a function of $\mathrm{M}_{\mathrm{g}}$. The resonant frequency decreases slightly with increasing moisture content if $\mathrm{M}_{\mathrm{g}}$ is less than $14 \%$. However, over that same range of $\mathrm{M}_{\mathrm{g}}, Q_{d}$ decreases significantly. For large values of $\mathrm{M}_{\mathrm{g}}$, the resonant frequency decreases 
significantly, but $Q_{d}$ is nearly constant. Thus, there is an advantage to using $f_{n} / f_{\text {air }}$ and $Q_{d}$ to analyze soil.

\section{SENSOR IMPLEMENTATION}

This sensor was developed under a project titled "MAHRS: A simple instrument suite to characterize weathering and the habitability of the shallow Martian subsurface" under the NASA Maturation of Instruments for Solar System Exploration (MATISSE) program. In addition to the brine sensor described in this paper, the project developed an optical microscope, a radiometer, a saltation sensor and an electric field sensor. The project envisions the brine sensor and the optical microscope placed on a robotic arm that would hold the sensors over or placed on top of the Mars surface. Because the brine sensor detects the phase change of brine from frozen to liquid by detecting variations in the resonant frequency and the quality factor of the resonance, it is important that the distance between the sensor and the surface be constant so that any measured variations are attributed to the phase change and not the measurement setup. The superstrate placed over the sensor protects the ring resonator so the brine sensor may be placed in contact with the soil as it was done in the experiments described in this paper. This may eliminate variations in the measurement conditions.

The original plan was for the electronics for the brine sensor to be placed inside the rover where they would be shielded from the extreme temperature variations. However, this required an RF transmission line or waveguide to be run from the rover to the sensor on the end of the arm and there were concerns about the reliability of the elbow on the RF cable. Therefore, the current design is for the RF and microcontroller circuits for the brine sensor to be placed in an enclosure attached to the ring resonator; only dc power lines and data input/output lines are run between the rover and the sensor at the end of the arm. This may require a heater to be placed within the enclosure, and further tests will be conducted to determine if that is needed.

To minimize data transfer, the microcontroller can perform the data analysis described in Section 3 and transmit either the resonant frequency and quality factor or the collected raw data within the narrow bandwidth around the resonant peaks. A determination will need to be made if transmitting the raw data is sufficiently valuable to justify storing and transmitting the data.

\section{Conclusions}

The measured characteristics of the ring resonator shown in this paper indicate that the sensor may detect the melting of a thin layer of frozen brine buried as deep as $15 \mathrm{~mm}$ below the surface. Admittedly, the change in resonant frequency is not large, on the order of $10 \mathrm{MHz}$ for the fundamental resonance, which will require a stable synthesizer with small frequency increment. Since the change in quality factor is larger, it should be able to be measured by most commercial power detector circuits, but a small frequency increment is still required to fit with the Lorentzian equation.

Multiple resonances were measured to determine if additional data may be obtained. If the sole purpose of the sensor is to detect the phase change from frozen to liquid water or brine in the shallow subsurface, the fundamental resonance is sufficient. However, from the buried ice experiments, there appears to be a variation in $Q_{d}$ for the three resonances, and this may yield information about the depth of the ice. If a better understanding of the permittivity of the brine versus temperature was available and the measurements were repeatable, it should be possible to determine the type of brine and/or its concentration through frequency spectroscopy.

It was observed that if the resonator is moved or it vibrates during the test, the measured results are affected. Since the change in frequency is very small, these affects due to movement yield wrong conclusions. Therefore, it is critical to hold the resonator still.

Further experiments to verify the sensor are planned. These include a sensor integrated with the RF circuits and the microcontroller and tested in a temperature controlled vacuum chamber to determine if a heater within the enclosure is needed. Also, Martian regolith simulants will be used to determine if the characteristics of the sand are sufficiently similar to Mars soil to justify the assumption made in Section 1 .

\section{ACKNOWLEDGEMENTS}

This work was funded by the NASA ASTID and the NASA MATISSE programs.

\section{REFERENCES}

[1] M. H. Hecht, S. P. Kounaves, R. C. Quinn, S. J. West, S. M. M. Young, D. W. Ming, D.C. Catling, B. C. Clark, and P. H. Smith, "Detection of perchlorate and the soluble chemistry of martian soil: Findings from the Phoenix Mars Lander," Science, 325 (5936), 2009.

[2] A. P. Zent, M. H. Hecht, D. R. Cobos, S. E. Wood, T. L. Hudson, S. M. Milkovich, L. P. DeFlores, and M. T. Mellon, "Initial results from the thermal and electrical conductivity probe (TECP) on Phoenix," Journal of Geophysical Research, Vol. 115, E00E14, 2010.

[3] N. O. Renno, B.J. Bos, D. Catling, B.C. Clark, L. Drube, D. Fisher, W. Goetz, S.F. Hviid, H. Keller, J.F. Kok, S.P. Kounaves, K. Leer, M. Lemmon, M. Bo Madsen, W. Markiewicz, J. Marshall, C. McKay, M. Mehta, M. Smith, M.P. Zorzano, P.H. Smith, C. Stoker, and S.M.M. Young, "Possible physical and thermodynamical evidence for liquid water at the 
Phoenix landing site," J. Geophys. Res., 114, E00E03, 2009.

[4] P.H. Smith, L. K. Tamppari, R.E. Arvidson, D. Bass, D. Blaney, W. V. Boynton, A. Carswell, D. C. Catling, B. Clark, T. Duck, E. DeJong, D. Fisher, W. Goetz, P. Gunnlaugsson, M. Hecht, V. Hipkin, J. Hoffman, S. Hviid, H. Keller, S. Kounaves, C. F. Lange, M. Lemmon, M. Madsen, M. Malin, W. Markiewicz, J. Marshall, C. McKay, M. T. Mellon, D. Ming, R. Morris, N. Renno, W.T. Pike, U. Staufer, C. Stoker, P. Taylor, J. Whiteway, and A. Zent, "H2O at the Phoenix landing site," Science, 325 (5936), 2009.

[5] D. E. Stillman and R. E. Grimm, "Dielectric signatures of absorbed and salty liquid water at the Phoenix landing site, Mars," Journ. of Geophysical Research, Vol. 116, E09005, 2011.

[6] J., Hanley, V. F. Chevrier, D. J. Berget, and R. D. Adams, "Chlorate salts and solutions on Mars," Geophys. Res. Lett., 39, L08201.

[7] E. Fischer, G. M. Martínez, H. M. Elliott and N. O. Rennó, "Experimental evidence for the formation of liquid saline water on Mars," Geophysical Research Lett., pp. 4456-4462, 2014.

[8] M. T. Hallikainen, F. T. Ulaby, M. C. Dobson, M. A. El-Rayes and L.-K. Wu, "Microwave dielectric behavior of wet soil-Part I: empirical models and experimental observations," IEEE Trans. On Geoscience and Remote Sensing, Vol- GE-23, No. 1, pp. 25-34, Jan. 1985.

[9] G. C. Topp, J. L. Davis and A. P. Annan, "Electromagnetic determination of soil water content: measurements in coaxial transmission lines," Water Resources Research, Vol. 16, No. 3, pp. 574-582, June 1980.

[10] M. Vall-Llossera, M. Cardona, S. Blanch, A. Camps, A. Monerris, I. Corbella, F. Torres and N. Duffo, "Lband dielectric properties of different soil types collected during the MOUSE 2004 field experiment," in Int. Geoscience and Remote Sensing Symp., Vol. 2, pp. 1109, July 2005.

[11] V. Mironov, Y. Kerr, J.-P. Wigneron, L. Kosolapova and F. Demontoux, "Temperature- and texturedependent dielectric model for moist soils at 1.4 GHz," IEEE Geoscience and Remote Sensing Lett., Vol. 10, No. 3, pp. 419-423, May 2013.

[12] C. Mätzler, "Microwave permittivity of dry sand," IEEE Trans. Geoscience and Remote Sensing, Vol. 36, No. 1, pp. 317-319, Jan. 1998.

[13]U. Kaatze, "Complex permittivity of water as a function of frequency and temperature," J. Chem. Eng. Data, Vol. 34, pp. 371-374, 1989.

[14] W. J. Ellison, "Permittivity of pure water, at standard atmospheric pressure, over the frequency range $0-25$ $\mathrm{THz}$ and temperature range $0-100{ }^{\circ} \mathrm{C}, " J$. Phys. Chem. Ref. Data, Vol 36, No. 1, pp. 1-18, 2007.
[15]J. H. Jiang and D. L. Wu, "Ice and water permittivities for millimeter and sub-millimeter remote sensing applications," Atmospheric Science Lett., pp. 146-151, 2004.

[16] W. Ho and W. F. Hall, "Measurements of the dielectric properties of seawater and $\mathrm{NaCl}$ solutions at $2.65 \mathrm{GHz}$," Journ. Of Geophysical Research, Vol. 78, No. 27, pp. 6301-6315, Sept. 20, 1973.

[17] L. A. Klien and C. T. Swift, "An improved model for the dielectric constant of sea water at microwave frequencies," IEEE Trans. Ant. and Propag., Vol. AP-25, No. 1, pp. 104-111, Jan 1977.

[18] W. Ellison, A. Balana, G. Delbos, K. Lamkaouchi, L. Eymard, C. Guillou and C. Prigent, "New permittivity measurements of seawater," Radio Science, Vol 33, No. 3, pp. 639-648, May-June 1998.

[19] A. Stogryn and G. J. Desargant, "The dielectric properties of brine in sea ice at microwave frequencies," IEEE Trans. Ant. and Propag., Vol. AP-33, No. 5, pp. 523-532, May 1985.

[20] S. Fujita, T. Matsuoka, T. Ishida, K. Matsuoka and S. Mae, "A summary of the complex dielectric permittivity of ice in the megahertz range and its applications for radar sounding of polar ice sheets," Physics of Ice Core Records, Ed. By T. Hondoh, Hokkaido University Press, 2000, Sapporo.

[21]M. R. Vant, R. O. Ramseier and V. Makios, "The complex-dielectric constant of sea ice at frequencies in the range 0.1-40 GHz," Journ. Applied Physics, Vol. 49, pp. 1264-1280, March 1978.

[22]B. Will, M. Gerding. T. Musch and I. Rolfes, "Determination of soil moisture based on an improved sensor design using time domain transmission measurements," Proc. $41^{\text {st }}$ European Micro. Conf., Oct 10-13, 2011, Manchester, UK, pp. 218-221.

[23]B. Will and M. Gerding, "Determination of the permittivity of soils by use of double transmission measurements," Adv. Radio Sci., Vol 7, pp. 104, 2009.

[24]M. Dionigi, A. Ocera, E. Fratticcioli and R. Sorrentino, "A new resonant probe for dielectric permittivity measurement," Proc. $34^{\text {th }}$ European Micro. Conf., 2004, Amsterdam, pp. 673-676.

[25]F. Sagnard and Y.-L. Beck, "Experimental study of the influence of moisture and dry density on a silt soil using a monopole probe," Micro. and Optical Techn. Lett., Vol. 51, No. 3, March 2009, pp. 820-826.

[26] G. Kitić and V. Crnojević-Bengin, "A sensor for the measurement of the moisture of undisturbed soil samples," Sensors, Vol. 13, 2013, pp. 1692-1705.

[27] W. Skierucha and A. Wilczek, "A FDR sensor for measuring complex soil dielectric permittivity in the 10-500 MHz frequency range," Sensors, Vol. 10, 2010, pp. 3314-3329.

[28] J. R. Birchak, C. G. Gardner, J. E. Hipp and J. M. Victor, "High dielectric constant microwave probes 
for sensing soil moisture," Proc. IEEE, Vol. 62, No. 1, pp. 93-98, Jan. 1974.

[29] D. A. Robinson, C. M. K. Gardner, J. Evans, J. D. Cooper, M. G. Hodnett and J. P. Bell, "The dielectric calibration of capacitance probes for soil hydrology using an oscillation frequency response model," Hydrology and Earth System Sciences, Vol. 2(1), 1998, pp. 111-120.

[30] E. Fratticcioli, M. Dionigi and R. Sorrentino, "A simple and low-cost measurement system for the complex permittivity characterization of materials," IEEE Trans. Instru. And Measur., Vol. 53, No. 4, pp. 1071-1077, Aug. 2004.

[31] E. Fratticcioli, M. Dionigi and R. Sorrentino, "A new permittivity model for the microwave moisture measurement of wet sand," European Microwave Conf., Munich, Germany, 2003, pp. 539-542.

[32]A. Ocera, E. Fratticcioli, M. Dionigi and R. Sorrentino, "A novel technique for measuring onedimensional permittivity profiles using a simple noncommensurate planar structure," IEEE Micro. and Wireless Comp. Lett., Vol. 18, No. 3, pp. 155-157, March 2008.

[33] C.-S. Lee and C.-L. Yang, "Complementary split-ring resonators for measuring dielectric constants and loss tangents," IEEE Micro. and Wireless Comp. Lett., Vol. 24, No. 8, pp. 563-565, Aug. 2014.

[34] K. Sarabandi and E. S. Li, "Microstrip ring resonator for soil moisture measurements," IEEE Trans. Geoscience and Remote Sensing, Vol. 35, No. 5, pp. 1223-1231, Sept. 1997.

[35] C. Guo and R. C. Liu, "Development of a micro-strip resonator soil moisture sensor," $14^{\text {th }}$ Int. Conf. Ground Penetrating Radar (GPR), June 4-8, 2012, Shanghai, China, pp. 676-679.

[36] Rogers Corporation, Publication \#92-108, TMM Thermoset Microwave Materials.

[37] Rogers Corporation, Publication \#92, Low Outgassing characteristics of Rogers laminates approved for spacecraft applications.

[38] http://marsnews.com/the-planet-mars, downloaded April 9, 2015.

[39] I. Wolff, "Microstrip bandpass filter using degenerate modes of a microstrip ring resonator," Electron. Lett., 15 June, 1972, Vol. 8, No. 12, pp. 302-303.

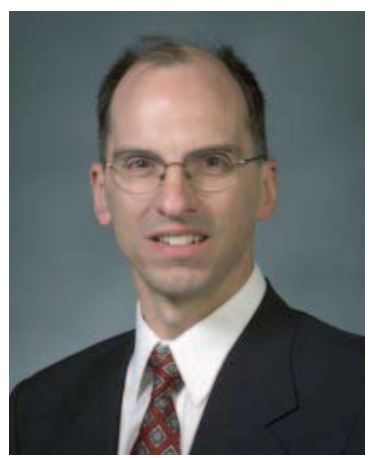

\section{BIOGRAPHIES}

George E. Ponchak ( $S^{\prime} 82$ - M'83 - SM'97-F'08) received the B. E. E. degree from Cleveland State University, Cleveland, $\mathrm{OH}$ in 1983, the M.S.E.E. degree from Case Western Reserve University, Cleveland, $\mathrm{OH}$ in 1987, and the Ph.D. in electrical engineering from the University of Michigan, Ann Arbor, MI in 1997.
He joined the staff of the Communications, Instrumentation, and Controls Division at NASA Glenn Research Center, Cleveland, OH in 1983 where he is now a senior research engineer. In 1997-1998 and in 2000-2001, he was a visiting professor at Case Western Reserve University in Cleveland, OH. He has authored and co-authored 200 papers in refereed journals and symposia proceedings.

Dr. Ponchak is a Fellow of the IEEE and an Associate Member of the European Microwave Association. Dr. Ponchak was the Editor-in-Chief of the IEEE Transactions Microwave Theory and Techniques from 2010-2013, the Editor-in-Chief of the IEEE Microwave and Wireless Components Letters from 2006-2009.

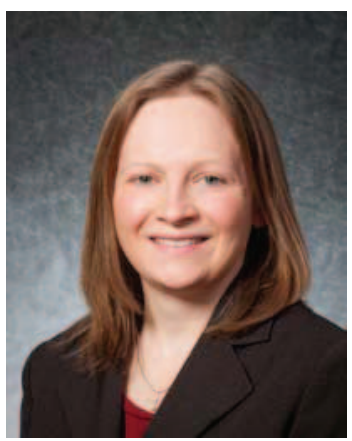

Jennifer L. Jordan ( $S^{\prime} 00-M^{\prime} 05-$ SM'14) received the B.S.E.E degree from Ohio Northern University in Ada, OH in 2005 and the M.S.E.E. degree from Case Western Reserve University in Cleveland, $\mathrm{OH}$ in 2014.

In 2005, she joined the staff of the Communications and Intelligent Systems Division at the NASA Glenn Research Center in Cleveland, OH. Currently, Ms. Jordan is a research engineer in the Smart Sensors and Electronics Systems Branch at NASA $G R C$, where she is currently works in the area of electronics for harsh environments. She has authored and co-authored numerous papers in refereed journals and symposia proceedings.

Ms. Jordan is a Senior Member of the IEEE and currently serves as the Treasurer of the IEEE Cleveland $A P / E D / M T T$ joint chapter and Secretary of the IEEE Cleveland Section.

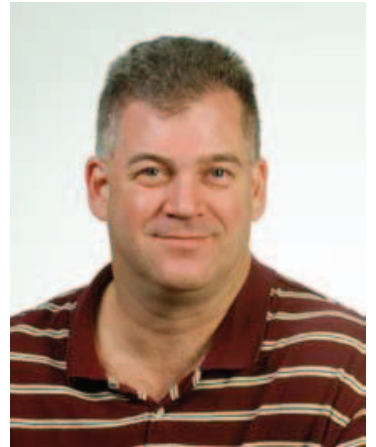

Maximilian C. Scardelletti is a senior research engineer in the Communications and Intelligent System Design Division at NASA Glenn Research Center in Cleveland, Ohio. He received his $B S E E$ and MSEE from the University of South Florida, Tampa, Florida, in 1997 and 1999, respectively. He is currently enrolled at Case Western Reserve University, Cleveland, Ohio where he is working towards his Doctoral degree in wireless electronics for harsh environments. He has co-authored over 50 articles in technical journals and conferences. Currently he is working on wireless sensor test beds for harsh environments. He is a Senior Member of IEEE and the chair of the IEEE Cleveland $A P / E D / M T T$ joint chapter and the Treasurer of the IEEE Cleveland section. 